\title{
Método RÁpido para Detecção de Resistência de CAPIM-ARRoz (Echinochloa spp.) AO QUINCLORAC ${ }^{1}$
}

\author{
A Quick Method for Detecting Resistance of Echinochloa spp. to Quinclorac
}

\author{
CONCENÇO, G. ${ }^{2}$, MELO, P.T.B.S..$^{3}$, ANDRES, A. ${ }^{4}$, FERREIRA, E.A. ${ }^{2}$, GALON, L. $^{2}$, FERREIRA, F.A. ${ }^{5}$ e \\ SILVA, A.A. ${ }^{5}$
}

\begin{abstract}
RESUMO - Considerando-se que a resistência de capim-arroz ao quinclorac está amplamente distribuida nas lavouras do Rio Grande do Sul e de Santa Catarina e que o "teste-padrão" para distinção de biótipos resistentes a esse herbicida é demorado, torna-se necessário o desenvolvimento de um "teste rápido" para identificação de propágulos desses biótipos. Para isso, foram realizados dois experimentos: um em casa de vegetação (teste-padrão) e o outro em laboratório (teste rápido). No ensaio em laboratório, sementes de quatro biótipos de capim-arroz, caracterizados como resistentes ou suscetiveis ao quinclorac, foram semeadas em papel germitest umedecido com soluções de $0 ; 3,75 ; 18,75 ; 37,5 ; 187,5 ; 375$; e $1.875 \mathrm{mg} \mathrm{L}^{-1}$ do herbicida durante 14 dias a $25^{\circ} \mathrm{C}$. Em casa de vegetação, os mesmos tratamentos foram avaliados cultivando-se os biótipos de capim-arroz em vasos com $10 \mathrm{~L}$ de solo. Neste ensaio foram avaliados massa seca e altura de plantas aos 25 dias após emergência (DAE), e no ensaio em laboratório, percentagem de sobrevivência aos 7 dias após semeadura (DAS), massa seca e comprimento da parte aérea das plantas aos 14 DAS. O teste em laboratório é mais rápido, exige menos tempo, recursos humanos e materiais, com a mesma eficiência que o teste em casa de vegetação e com a vantagem adicional de permitir aferições quanto ao nivel de resistência entre biótipos resistentes. Sugere-se que a concentração de $375 \mathrm{mg} \mathrm{L}^{-1}$ de quinclorac seja usada como padrão no teste rápido, pois apresenta adequada margem de segurança como indicadora da presença de sementes resistentes, com porcentagem de sobrevivência igual a zero para plântulas dos biótipos suscetiveis ao quinclorac.
\end{abstract}

Palavras-chave: Echinochloa, resistência, identificação.

\begin{abstract}
Given that resistance of Echinochloa sp. to quinclorac is widely distributed in rice fields in the states of Rio Grande do Sul and Santa Catarina, and that the standard tests are relatively slow in showing resistance, a quick test must be developed to identify seeds from Echinochloa plants resistant to quinclorac. The trials were conducted under greenhouse and germination chamber conditions. In the germination chambertrial, seeds of four Echinochloa biotypes, characterized as resistant or susceptible to quinclorac, were sown at concentrations of $0,3.75$, $18.75,37.5,187.5,375$ and $1875 \mathrm{mg} \mathrm{L}^{-1}$ of quinclorac, and the trial was conducted at $25^{\circ} \mathrm{C}$ for 14 days. Under greenhouse conditions, the same biotypes were sown and treated with rates of 0 , 5.5, 187.5, 375, 750, 1500 and $3000 \mathrm{~g} \mathrm{ha}{ }^{1}$ of quinclorac. Under greenhouse conditions, dry mass and plant height were evaluated 25 days after emergence, and under germination chamber conditions, dry mass and plant height were evaluated 14 days after sowing (DAS), with survival being evaluated 7 DAS. The quick test required less time, labor and material, being as efficient as the greenhouse trial. In addition, it could differentiate both resistant biotypes in function of the resistance level. It is suggested that the concentration of $375 \mathrm{mg} \mathrm{L}^{-1}$ of quinclorac be used as the standard for the quick test, since it showed an adequate safety margin in separating seeds from the resistant and susceptible biotypes.
\end{abstract}

Keywords: Echinochloa, resistance, identification.

1 Recebido para publicação em 27.5.2007 e na forma revisada em 20.3.2008.

2 Doutorando em Fitotecnia/UFV, Viçosa-MG, bolsista CNPq, <gconcenco@yahoo.com.br>; ${ }^{3}$ Engo-Agr ${ }^{-}$., Dr., Dep. de Sementes, Faculdade de Agronomia Eliseu Maciel, UFPel, Pelotas-RS; ${ }^{4}$ Eng-o-Agr ${ }^{\circ}$., M.Sc., Pesquisador da área de herbologia da Embrapa Clima Temperado, Pelotas/RS; ${ }^{5}$ Prof., Dr., Dep. de Fitotecnia, UFV, Viçosa-MG, bolsista CNPq. 


\section{INTRODUÇÃO}

A cultura do arroz, especialmente do irrigado, exerce grande expressão econômica nos Estados do Rio Grande do Sul e de Santa Catarina, com patamares de produtividade em torno de 5,6 e 7,5 t ha ${ }^{-1}$, respectivamente (Andres $\&$ Machado, 2004). As plantas daninhas são responsáveis por perdas substanciais de produtividade das culturas, quando não corretamente manejadas. A diversidade de espécies, aliada à alta infestação, dificulta o controle, ocasiona problemas durante o cultivo, facilita o acamamento da cultura e dificulta outros tratos culturais, além de causar maiores perdas na colheita (Fleck et al., 2004).

O capim-arroz (Echinochloa spp.) é considerado uma das espécies daninhas mais problemáticas do arroz irrigado, por estar amplamente distribuído, ser de crescimento agressivo e apresentar similaridade morfológica com as plantas da cultura, o que dificulta a aplicação de métodos alternativos de controle (Andres et al., 2007). Altas infestações de capim-arroz podem causar reduções de até $90 \%$ no rendimento de grãos da cultura (Melo et al., 2006).

Dentre os herbicidas utilizados na lavoura de arroz, o quinclorac, mimetizador de auxina, reúne flexibilidade na aplicação (pré e pósemergência), eficiência de controle de Echinochloa spp. e Aeschynomene spp., baixa toxicidade ao homem e aos animais e seletividade à cultura do arroz (Andres et al., 2002a) . Esse princípio ativo começou a ser utilizado nas regiões orizícolas dos Estados do Rio Grande do Sul e de Santa Catarina no início da década de 1990, sendo usado intensamente até meados de 1999, quando começaram a surgir queixas sobre falhas de controle de capimarroz. Estudos realizados por instituições do Sul do País confirmaram a ocorrência de resistência (Eberhardt et al., 2000; Menezes \& Ramirez, 2000; Andres et al., 2002b) e sua ampla distribuição (Andres et al., 2007).

Algumas espécies e alguns biótipos de Echinochloa no sul da Europa e Estados Unidos apresentam variações naturais de sensibilidade ao herbicida quinclorac, e esse fato independe do histórico de aplicação deste herbicida (Heap, 2007). Grossmann (1998) afirma que raízes de capim-arroz intactas foram apenas três vezes mais sensiveis ao quinclorac que raizes de arroz, afirmando ainda que a parte aérea é a principal responsável pela seletividade.

Trabalhos preliminares conduzidos na Embrapa Clima Temperado (Andres et al., 2002a, b) indicam a ocorrência de biótipos de capim-arroz resistentes ao quinclorac com maior ou com menor velocidade de germinação e crescimento inicial que o biótipo suscetivel, em função principalmente do local de origem. Logo, esses biótipos podem tanto ter desaparecido das lavouras com o tempo, como ter mantido ou incrementado sua frequência na população na ausência do agente selecionador (Christoffoleti et al., 1994; Walsh et al., 2001). Além disso, suspeitas recentes quanto à evolução de resistência de capim-arroz aos herbicidas inibidores da enzima acetolactato sintase (ALS) tendem a limitar o leque de produtos disponiveis para controle de capim-arroz, uma vez que a grande maioria dos produtos atualmente recomendados para esse fim são inibidores da ALS (Andres et al., 2002a). Em áreas onde a resistência ao quinclorac não está presente, este produto poderia ser utilizado em sistema de rotação de princípios ativos, para evitar o surgimento de biótipos resistentes a ambos os grupos químicos (Eerd et al., 2004; Vargas et al., 2005).

O método-padrão adotado para comprovação da resistência normalmente é o bioensaio em casa de vegetação, sendo os biótipos com suspeita de resistência semeados em vasos contendo $10 \mathrm{~L}$ de solo e as plantas conduzidas por 15 dias após a emergência, quando então se realiza a aplicação de dose elevada de quinclorac (Andres et al., 2007). O tempo gasto para isso é de aproximadamente 30 dias, levando em consideração os períodos de pré-emergência, pré-aplicação e avaliação (Andres et al., 2002b).

Objetivou-se neste trabalho desenvolver metodologia que permita a detecção da resistência de capim-arroz ao quinclorac em menor tempo e menos uso de recursos humanos e de material.

\section{MATERIAL E MÉTODOS}

Em casa de vegetação climatizada, foi utilizado o processo tradicional para detecção de resistência, em delineamento experimental 
de blocos casualizados com cinco repetições. As unidades experimentais constaram de vasos de polietileno contendo $10 \mathrm{~L}$ de solo corrigido e adubado segundo análise de solo. Dez sementes de capim-arroz foram semeadas por unidade experimental, e a emergência ocorreu quatro dias após a semeadura. O desbaste foi realizado cinco dias após a emergência (DAE), deixando seis plantas por vaso.

Os tratamentos constaram de doses de quinclorac $(0 ; 5,5 ; 187,5 ; 375 ; 750 ; 1.500 \mathrm{e}$ $3.000 \mathrm{~g} \mathrm{ha}^{-1}$ ) aplicadas aos 10 DAE sobre dois biótipos resistentes ao quinclorac (ETB-13 e ETB 14) e dois suscetiveis de referência (ETB00 e ETB-11) obtidos em áreas sem histórico de aplicação de mimetizadores de auxina. Os tratamentos foram aplicados com pulverizador costal propelido $\mathrm{CO}_{2}$, equipado com ponta tipo leque 110.015, espaçadas de 0,5 m. Durante as aplicações manteve-se pressão constante de 28 psi, sendo aplicado o equivalente a $150 \mathrm{~L} \mathrm{ha}^{-1}$ de calda.

Foram avaliadas a altura de plantas e a massa seca aos 25 DAE. A altura foi aferida com auxílio de régua graduada, expressa em centímetros, sendo composta pela média aritmética da aferição das seis plantas em cada unidade experimental. A massa seca (MS) foi determinada para as seis plantas de cada unidade experimental, sendo elas cortadas rente ao solo e imediatamente acondicionadas em saco de papel, colocado na estufa de circulação forçada de ar a $60^{\circ} \mathrm{C}$ até massa constante.

Os dados foram verificados quanto à normalidade e homogeneidade. Depois disso, foram submetidos à análise de variância pelo teste $\mathrm{F}$ a $5 \%$. No caso de significância estatística, foi efetuada análise de regressão com modelos não-lineares (Pimentel-Gomes, 1987).

Em laboratório, outro experimento foi realizado em câmara de germinação tipo Mangelsdorf, regulada para temperatura constante de $25{ }^{\circ} \mathrm{C}$. Utilizou-se o delineamento experimental completamente casualizado, com cinco repetições de 50 sementes por biótipo. Papéis germitest foram embebidos nas soluções de quinclorac $(0 ; 3,75 ; 18,75 ; 37,5 ; 187,5 ; 375$; e $1.875 \mathrm{mg} \mathrm{L}^{-1}$ ) durante 24 horas. Após esse período, o excesso de solução foi drenado, sendo semeados dois biótipos resistentes ao quinclorac (ETB-13 e ETB-14), e os dois suscetiveis de referência (ETB-00 e ETB-11) foram obtidos em áreas sem histórico de aplicação de mimetizadores de auxina. As unidades experimentais foram acondicionadas individualmente em saco plástico fechado e colocadas aleatoriamente no interior do germinador em posição vertical.

As porcentagens de germinação e de sobrevivência foram avaliadas sete dias após semeadura (DAS). Aos 14 DAS, foram avaliados ainda o comprimento das plantas e a massa seca. O comprimento foi aferido com auxílio de régua graduada, expressa em centímetros, sendo composta pela média aritmética da aferição de 10 plantas representativas em cada unidade experimental. A massa seca (MS) foi determinada para 10 plantas de cada unidade experimental, sendo imediatamente acondicionadas em sacos de papel, os quais foram colocados na estufa de circulação forçada de ar a $60^{\circ} \mathrm{C}$ até massa constante. Nas avaliações de germinação, foram consideradas apenas as plantas que permaneceram vivas após a germinação, uma vez que todas as sementes germinaram, independentemente de dose e de serem originadas ou não de biótipo resistente. Plântulas mortas e com presença de algum tipo de anomalia fenotípica foram desconsideradas nas avaliações de massa seca e comprimento de plantas.

Os dados obtidos foram verificados quanto à normalidade e homogeneidade e submetidos à análise de variância pelo teste $\mathrm{F}$ a $5 \%$. No caso de significância estatística, foi efetuada análise de regressão com modelos não-lineares (Pimentel-Gomes, 1987).

\section{RESULTADOS E DISCUSSÃO}

Em casa de vegetação, os biótipos suscetíveis ao herbicida quinclorac (ETB-00 e ETB 11) reduziram o acúmulo de massa seca por planta a partir da menor dose, sendo o efeito mais pronunciado a partir da dose de $187,5 \mathrm{~g} \mathrm{ha}^{-1}$, que corresponde a 0,5 vez a dose recomendada pela pesquisa para controle de capim-arroz (Figura 1). Na menor dose de quinclorac, a redução no acúmulo de massa dos biótipos suscetiveis foi em torno de $50 \%$ em relação à testemunha sem aplicação. A dose de $375 \mathrm{~g} \mathrm{ha}^{-1}$ aplicada sobre os biótipos suscetíveis causou morte total das plantas, enquanto os biótipos 


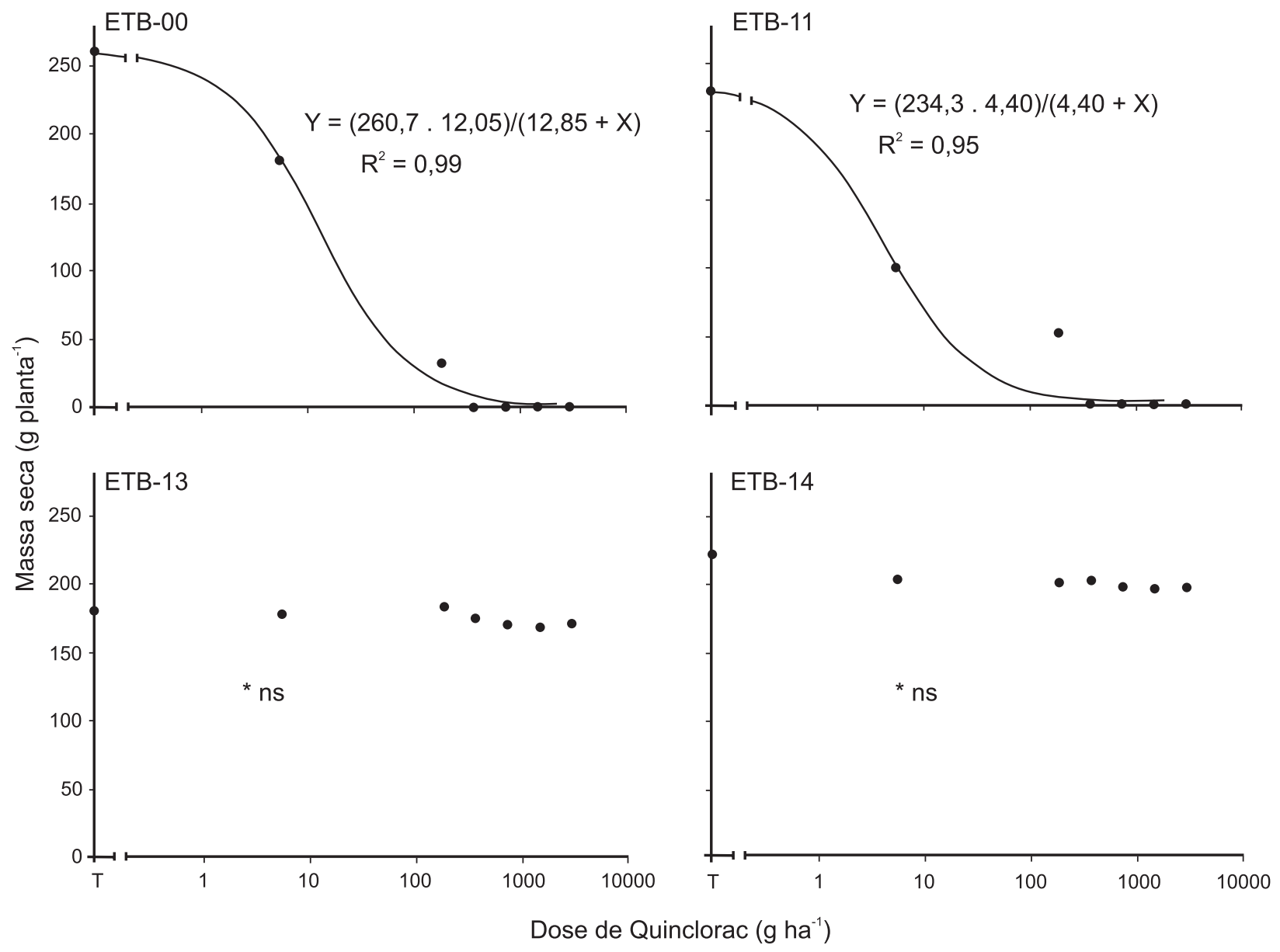

Figura 1 - Massa seca da parte aérea de plantas de capim-arroz cultivadas em casa de vegetação, aos 25 dias após emergência, em função de biótipos e doses de quinclorac.

comprovadamente resistentes foram capazes de suportar a dose de $3.000 \mathrm{~g} \mathrm{ha}^{-1}$ (8x a dose recomendada). Nestas plantas não se observaram alterações no acúmulo de massa ou sintomas aparentes de intoxicação, como amarelecimento, necrose ou murcha. Como conseqüência, o Îndice de Resistência (RI) destes biótipos deverá ser superior a 8 (Valverde et al., 2000).

$\mathrm{Na}$ testemunha sem aplicação do herbicida, todos os biótipos apresentaram massa seca por planta equivalente a aproximadamente $200-250 \mathrm{~g} \mathrm{planta}^{-1}$, indicando que o vigor de desenvolvimento das plantas pode ser equivalente tanto para os biótipos suscetiveis como para os resistentes ao quinclorac (Figura 1).

Plantas com menor altura $(\mathrm{p} \leq 0,05)$ também foram observadas nos biótipos suscetiveis. De modo semelhante à massa seca de plantas, a altura foi alterada a partir da menor dose, obtendo-se controle satisfatório a partir da dose de $187,5 \mathrm{~g} \mathrm{ha}^{-1}$ e morte total das plantas com a dose de $375 \mathrm{~g} \mathrm{ha}^{-1}$ (Figura 2). O valor observado nas testemunhas, tanto dos biótipos resistentes como dos suscetíveis, também foi similar, indicando compatibilidade no vigor de emergência e crescimento inicial (Figura 2). Os biótipos resistentes não mostraram alteração na altura de plantas em função do aumento da dose de quinclorac até $3.000 \mathrm{~g}_{\text {ha }}{ }^{1}$.

Em laboratório, os biótipos suscetiveis tiveram o acúmulo de massa reduzido a partir da concentração de $3,75 \mathrm{mg} \mathrm{L}^{-1}$ de quinclorac, ocorrendo morte total das plantas a partir de 187,5 e $375 \mathrm{mg} \mathrm{L}^{-1}$ para os biótipos ETB-00 e ETB-11, respectivamente (Figura 3). Ao contrário do observado em casa de vegetação, os biótipos comprovadamente resistentes (ETB-13 e 


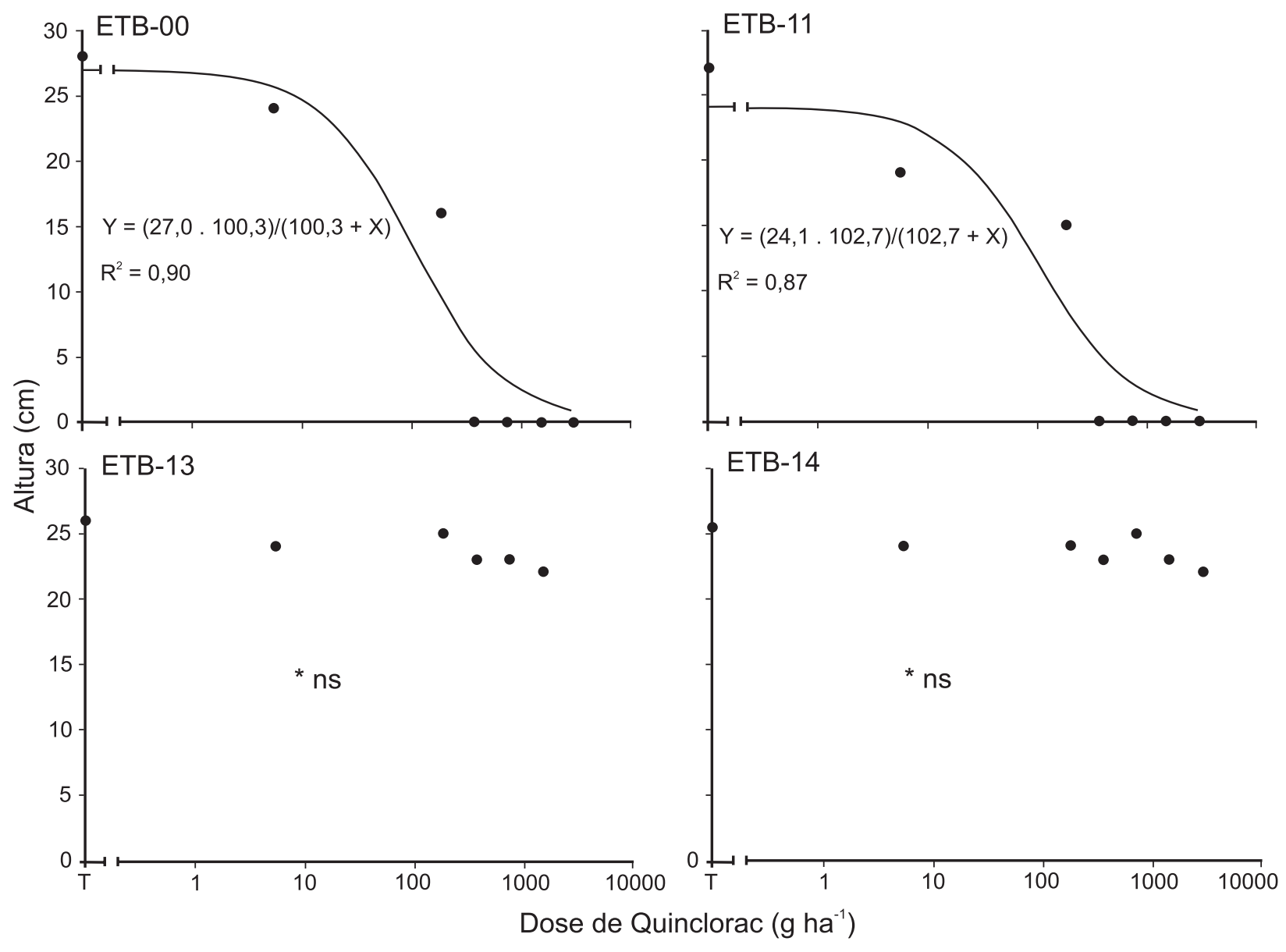

Figura 2 - Altura da parte aérea de plantas de capim-arroz cultivadas em casa de vegetação, aos 25 dias após emergência, em função de biótipos e doses de quinclorac.

ETB-14) tratados com o quinclorac tiveram o acúmulo de massa seca reduzido com o incremento na concentração do herbicida. O biótipo ETB-13 apresentou valor de massa seca ao redor de $26 \%$ do valor observado para a testemunha sem aplicação, enquanto o biótipo ETB14 mostrou valores em torno de $74 \%$ do observado para a testemunha sem aplicação (Figura 3). Como conseqüência, foi possível ainda observar distinção quanto ao nivel de resistência ao quinclorac. O biótipo ETB-13 apresentou resistência intermediária, devido à drástica redução no acúmulo de massa na maior dose, quando comparado à testemunha, e o biótipo ETB-14 foi classificado como altamente resistente, em virtude da pequena variação nos valores de massa seca na maior dose, quando comparado à testemunha sem aplicação (Figura 3). Os testes realizados em ambiente controlado normalmente são mais precisos e conclusivos que os de casa de vegetação ou em campo, em razão da maior possibilidade de controle das variáveis do ambiente e do menor coeficiente de variação (Magalhães Jr. et al., 2000).

O comprimento de plantas mostrou comportamento similar ao da massa seca; plantas menores foram observadas a partir da concentração de 3,75 $\mathrm{mg} \mathrm{L}^{-1}$ de quinclorac. Ambos os biótipos suscetiveis mostraram comportamento semelhante em função do incremento na dose do herbicida, ocorrendo morte total das plantas nas doses de 37,5 e $375 \mathrm{mg} \mathrm{L}^{-1}$ para os biótipos ETB-00 e ETB-11, respectivamente (Figura 4). Os biótipos resistentes mostraram redução no comprimento de plantas a partir das doses de 18,75 e $37,5 \mathrm{mg} \mathrm{L}^{-1}$, exibindo valores em torno de 80 e $90 \%$ do valor observado na testemunha sem aplicação, respectivamente. 


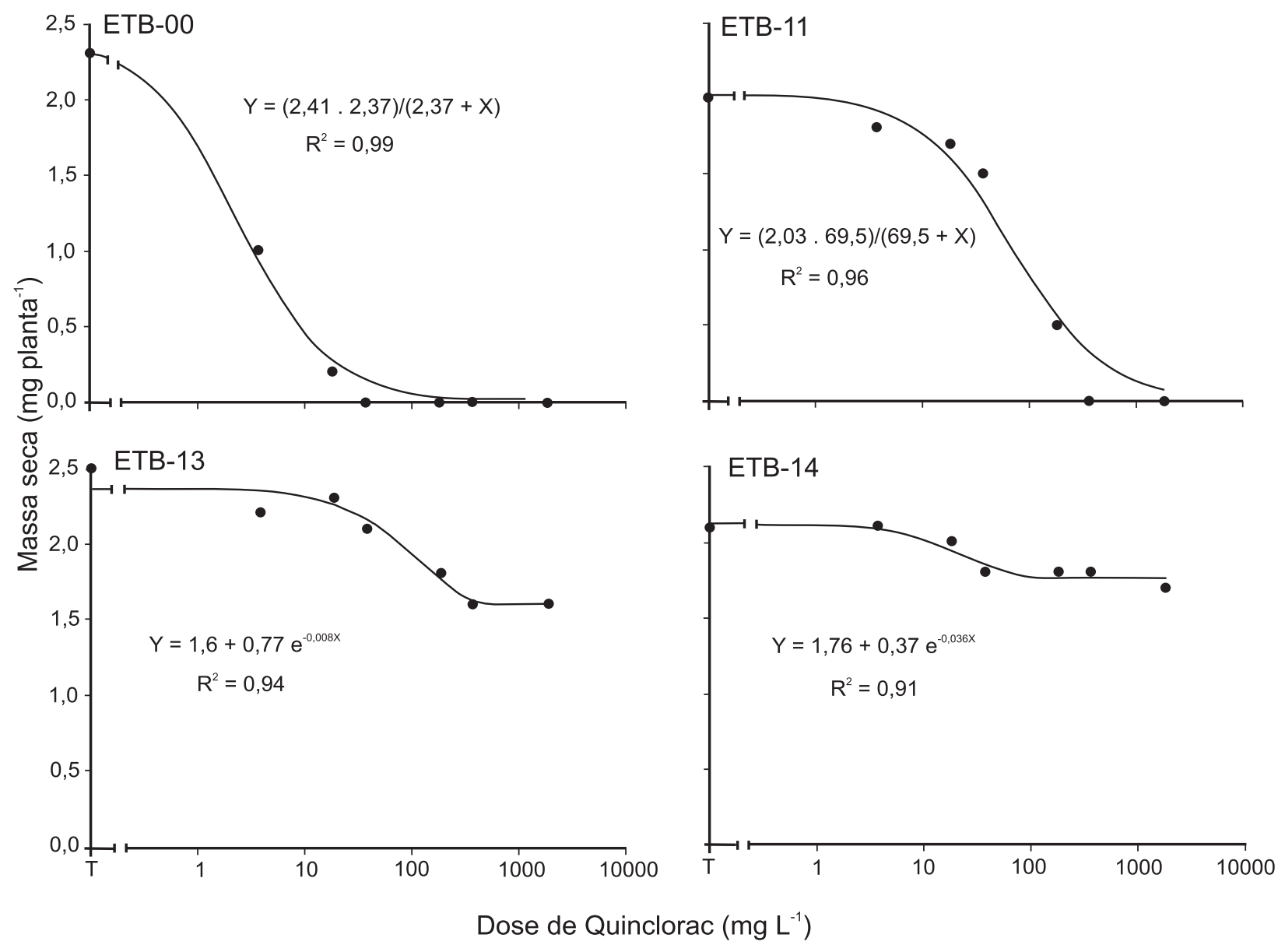

Figura 3 - Massa seca de plantas de capim-arroz cultivadas em câmara de crescimento, aos 14 dias após emergência, em função de biótipos e concentrações de quinclorac.

Além dos valores de massa seca e altura de plantas, em laboratório, foi possivel aferir a ocorrência de resistência aos sete dias após instalação do experimento através dos valores de sobrevivência (Figura 5), uma vez que as sementes permaneceram em ambiente com presença do herbicida desde a semeadura. $\mathrm{Na}$ primeira avaliação de germinação, realizada sete dias após semeadura (DAS), o resultado foi idêntico ao obtido na avaliação final, aos 14 DAS. Durante o processo de avaliação do teste de germinação, observou-se que as sementes germinavam independentemente da concentração utilizada. Entretanto, a morte ocorria em até cinco dias após a germinação, nas doses letais. Mesmo tendo sido detectadas diferenças quanto à germinação na contagem realizada aos 7 DAS, considera-se prudente conduzir o experimento até a contagem final, aos 14 DAS, devido a possiveis diferenças de comportamento entre biótipos (Magalhães Jr. et al., 2000).

Em casa de vegetação, praticamente nenhum efeito de dose foi observado para os biótipos resistentes (Figuras 1 e 2). Por outro lado, no teste realizado em laboratório, além da distinção entre biótipos resistentes e suscetíveis ao quinclorac, foi possivel aferir quanto ao nível de resistência entre biótipos resistentes (Figuras 3, 4 e 5). Os dados de germinação permitem tanto distinguir entre biótipos resistentes e suscetiveis, como o nivel de resistência entre os biótipos resistentes (Figura 5). Biótipos resistentes em casa de vegetação também mostraram o mesmo comportamento no experimento conduzido em câmara de crescimento, demonstrando que o teste rápido é eficiente 


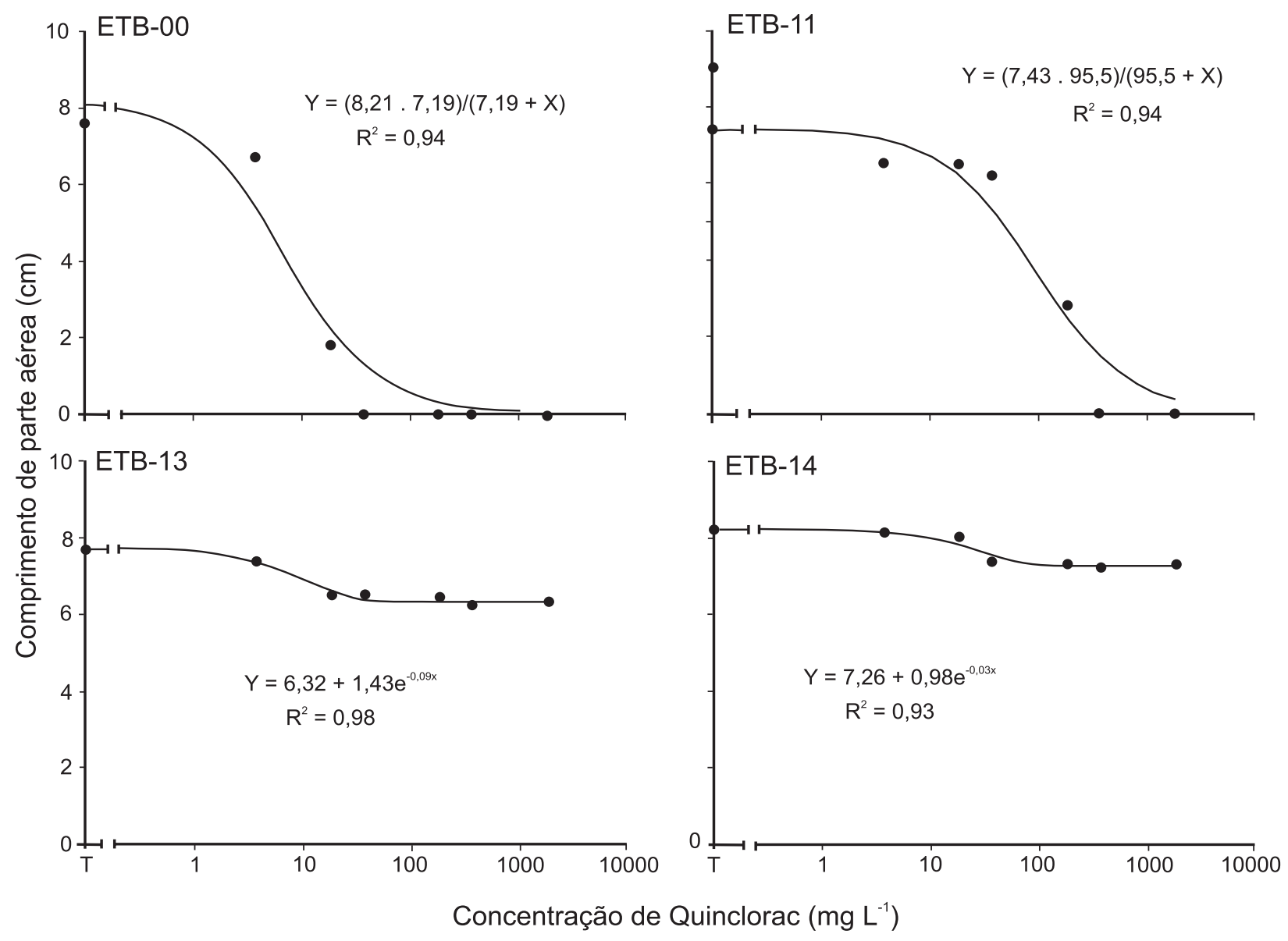

Figura 4 - Comprimento da parte aérea de plantas de capim-arroz cultivadas em câmara de crescimento, aos 14 dias após semeadura, em função de biótipos e concentrações de quinclorac.

na avaliação de sementes provindas de plantas resistentes. Em laboratório, o teste foi mais rápido, alcançando os primeiros resultados aos 7 DAS e o resultado final aos 14 DAS (Melo et al., 2003), enquanto para o experimento em casa de vegetação são necessários entre 30 e 35 dias para planejamento, implantação, avaliações e conclusões (Andres et al., 2002b).

Em laboratório, a demanda por recursos humanos e de material é menor, permitindo, conseqüentemente, avaliações de maior número de biótipos conjuntamente. Existem várias situações em que os testes rápidos podem ser utilizados. Muitas empresas os empregam como ferramenta de diagnóstico em falhas de controle de plantas daninhas com aplicação de seus produtos (Boutsalis, 2002). O teste rápido pode viabilizar a condução de estudos de ampla abrangência, semelhantes aos conduzidos por Andres et al. (2007), com 45 biótipos de capim-arroz com suspeita de resistência ao quinclorac, e por Walsh et al. (2001), monitorando simultaneamente 133 lavouras na Austrália.

O teste em laboratório é mais rápido, exige menos tempo, recursos humanos e materiais, com a mesma eficiência que o teste em casa de vegetação e com a vantagem adicional de permitir aferições quanto ao nivel de resistência entre biótipos resistentes. Sugere-se que a concentração de $375 \mathrm{mg} \mathrm{L}^{-1}$ de quinclorac seja usada como padrão no teste rápido, pois apresenta adequada margem de segurança como indicadora da presença de sementes resistentes, com porcentagem de sobrevivência igual a zero para plântulas dos biótipos suscetíveis ao quinclorac. 


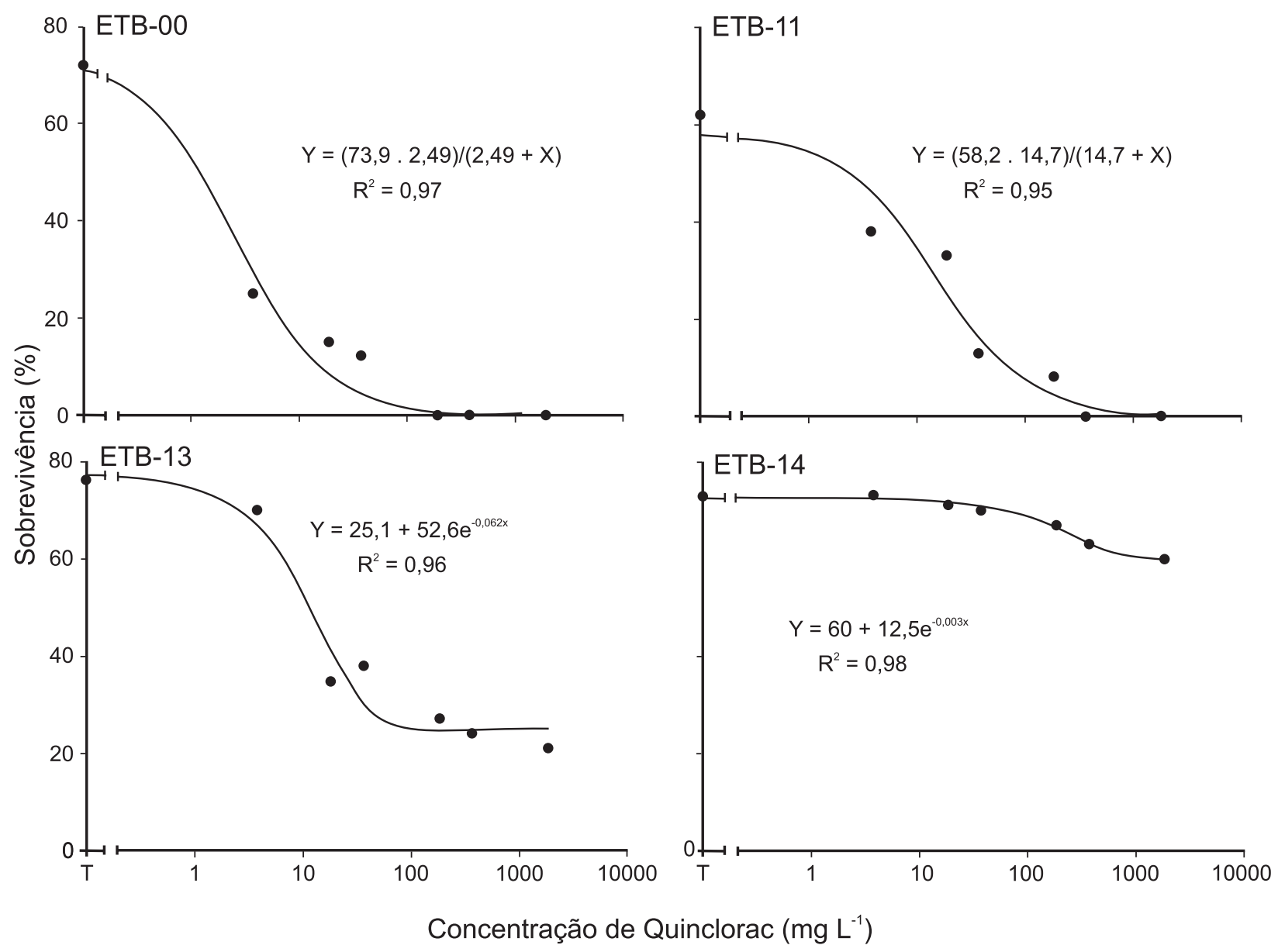

Figura 5 - Sobrevivência de plântulas de capim-arroz cultivadas em câmara de crescimento, aos 7 dias após semeadura, em função de biótipos e concentrações de quinclorac.

\section{LITERATURA CITADA}

ANDRES, A. et al. Uso de inibidores de tubulina, de ACCase e de ALS em arroz irrigado para o controle de capim-arroz resistente a quinclorac. In: CONGRESSO BRASILEIRO DA CIÊNCIA DAS PLANTAS DANINHAS, 23., 2002, Gramado. Resumos... Londrina: SBCPD/Embrapa Clima Temperado, 2002a. p. 203

ANDRES, A. et al. Avaliação de ecótipos de capim-arroz resistentes a quinclorac. In: CONGRESSO BRASILEIRO DA CIÊNCIA DAS PLANTAS DANINHAS, 23., 2002, Gramado. Resumos... Londrina: SBCPD/Embrapa Clima Temperado, 2002b. p. 192.

ANDRES, A.; MACHADO, S. L. O. Plantas daninhas em arroz irrigado. In: GOMES, A.S.; MAGALHÃES JR.; A. M. (Eds.). Arroz irrigado no Sul do Brasil. Brasília: Embrapa Informação Tecnológica, 2004. p. 457-546.
ANDRES, A. et al. Detecção da resistência de capim-arroz (Echinochloa sp.) ao herbicida quinclorac em regiões orizícolas do sul do Brasil. Planta Daninha, v. 25, n. 1, p. $221-226,2007$.

BOUTSALIS, P. Herbicida resistance - Quick test. LOCAL: Global Herbicide Resistance Support, 2002. CDROM.

CHRISTOFFOLETI, P. J.; VICTORIA FILHO, R.; SILVA, C. B. Resistência de plantas daninhas aos herbicidas. Planta Daninha, v. 12, n. 1, p. 13-20, 1994.

EBERHARDT, D. S. et al. Resistência de capim-arroz (Echinochloa crusgalli) ao herbicida quinclorac. In: CONGRESSO BRASILEIRO DA CIÊNCIA DAS PLANTAS DANINHAS, 22., 2000, Foz do Iguaçu. Resumos... Londrina: SBCPD/Embrapa Clima Temperado, 2000. p. 512. 
EERD, L. L. V. et al. Resistance to quinclorac and ALSinhibitor herbicides in Galium spurium is conferred by two distinct genes. Weed Res., v. 44, n. 5, p. 355-365, 2004.

FLECK, N. G. et al. Manejo e controle de plantas daninhas em arroz irrigado. In: VARGAS, L.; ROMAN, E. S. (Eds.). Manual de manejo e controle de plantas daninhas. Bento Gonçalves: Embrapa Uva e Vinho, 2004. p. 251-321.

GROSSMANN, K. Quinclorac belongs to a new class of highly selective auxin herbicides. Weed Sci., v. 46, n. 6, p. $707-716,1998$

HEAP, I. M. International survey of herbicide resistant weeds. Disponível em: <http://www.weedscience.org> Acesso em: 6 de abril 2007.

MAGALHÃES Jr., A. M. et al. Método para identificação de sementes de arroz transgênico resistente ao herbicida glufosinato de amônio. Pesq. Agropec. Bras., v. 3, n. 1, p. 31-38, 2000.

MELO, P. T. B. S. et al. Determinação de metodologia de laboratório para identificação de sementes de capim-arroz resistente ao herbicida quinclorac. In: INTERNATIONAL TEMPERATE RICE CONFERENCE, 3., 2003, Punta del Este. Proceedings... Punta del Este: INIA, 2003. CDROM.
MELO, P. T. B. S. et al. Comportamento de populações de arroz irrigado em função das proporções de plantas originadas de sementes de alta e baixa qualidade fisiológica.

R. Bras. Agroc., v. 12, n. 1., p. 37-43, 2006.

MENEZES, V. G.; RAMIREZ, H. V. Resistance of Echinochloa crus-galli L. to quinclorac in flooded rice in Southern Brazil. In: INTERNATIONAL WEED SCIENCE CONGRESS, 3., 2000, Foz do Iguaçu. Abstracts... Corvallis: IWSS, 2000. p. 140

PIMENTEL GOMES, F. P. A estatística moderna na pesquisa agropecuária. Piracicaba: POTAFOS, 1987. 160 p.

VALVERDE, B. E.; RICHES, C. R.; CASELEY, J. C. Prevention and management of herbicide-resistant weeds in rice: Experiences from Central America with Echinochloa colona. Costa Rica: Cámara de Insumos Agropecuarios, 2000. 123 p.

VARGAS, L. et al. Alteração das características biológicas dos biótipos de azevém (Lolium multiflorum) ocasionada pela resistência ao herbicida glyphosate. Planta Daninha, v. 23, n. 1, p. 153-160, 2005.

WALSH, M. J. et al. High frequency of chlorsulfuron resistant wild radish (Raphanus raphanistrum L.) populations across the Western Australian Wheatbelt. Weed Technol., v. 15, n. 2, p. 199-203, 2001. 